\title{
Impact of selective digestive decontamination without systemic antibiotics in a major heart surgery intensive care unit
}

\author{
María Jesús Pérez-Granda, RN, PhD, ${ }^{\mathrm{a}, \mathrm{b}, \mathrm{c}, \mathrm{d}}$ José M. Barrio, MD, PhD, ${ }^{\mathrm{a}, \mathrm{b}, \mathrm{d}}$ Javier Hortal, MD, PhD, a,b,d \\ Almudena Burillo, MD, PhD, ${ }^{\mathrm{c}, \mathrm{d}}$ Patricia Muñoz, MD, PhD, ${ }^{\mathrm{b}, \mathrm{d}, \mathrm{d}, \mathrm{e}}$ and Emilio Bouza, MD, $\mathrm{PhD}^{\mathrm{b}, \mathrm{c}, \mathrm{d}, \mathrm{e}}$
}

\begin{abstract}
Purpose: The incidence density of ventilator-associated pneumonia (VAP) is higher in patients undergoing major heart surgery than in other populations, despite the introduction of bundles of preventive measures, because many risk factors are not amenable to intervention. Selective digestive decontamination (SDD) has been shown to be efficacious for decreasing the frequency of VAP, although it has not been incorporated into the routine of most intensive care units. The objective of our study was to evaluate the efficacy of SDD without parenteral antibiotics for preventing VAP in a major heart surgery intensive care unit.
\end{abstract}

Methods: We compared the incidence of VAP before the introduction of SDD (17 months) and during the 17 months after the introduction of SDD and examined its ecologic influence.

Results: The rates of VAP in the overall population before and during the intervention were 16.26/1000 days and 6.80 episodes/1000 days of mechanical ventilation, respectively $(P=.01)$. The rates of VAP in the 173 patients remaining under mechanical ventilation $>48$ hours after surgery were, respectively, 25.85/1000 days of mechanical ventilation versus 12.06 episodes/1000 days of mechanical ventilation $(P=.04)$. We found a significant reduction in the number of patients with multidrug-resistant microorganisms $(P=.01)$ in the second period of the study.

Conclusions: Our study shows that SDD without parenteral antibiotics can reduce the incidence of VAP in high-risk patients after major heart surgery, with no significant ecologic influence. (J Thorac Cardiovasc Surg 2018;156:685-93)

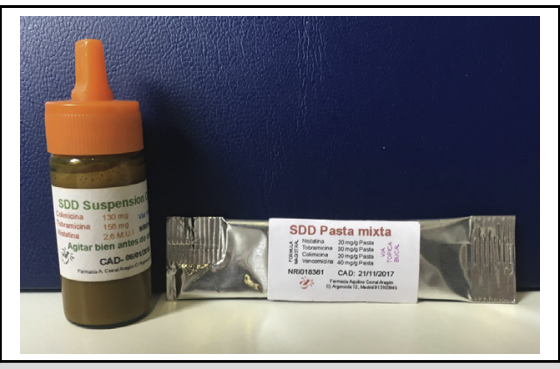

SDD digestive solution and oral paste.

Central Message

Our study evaluates the efficacy of SDD without parenteral antibiotics for preventing VAP in an MHS ICU and its ecologic influence.

Perspective

We found that SDD without parenteral antibiotics can reduce the incidence and delay onset of VAP in high-risk patients after MHS. The presence of MDR microorganisms had no ecologic influence on the MHS-ICU. In our opinion, SDD should be systematically applied to all patients requiring MV $>48$ hours after MHS.

See Editorial Commentary page 694.

\footnotetext{
From the a Department of Anesthesiology, Hospital General Universitario Gregorio Marañón, Madrid, Spain; ${ }^{\mathrm{b}}$ Ciber de Enfermedades Respiratorias CIBER (CB06/06/0058), Madrid, Spain; ${ }^{\mathrm{C} D e p a r t m e n t ~ o f ~ C l i n i c a l ~ M i c r o b i o l o g y ~ a n d ~ I n f e c-~}$ tious Diseases, Hospital General Universitario Gregorio Marañón and Universidad Complutense de Madrid, Spain; ${ }^{\mathrm{d}}$ Instituto de Investigación sanitaria Gregorio Marañón, Madrid, Spain; and ${ }^{\mathrm{e}}$ Department of Medicine, Universidad Complutense, Madrid, Spain.

Supported in part by Ciber de Enfermedades Respiratorias, the Rafael del Pino Foundation, and by grants from the Fondo de Investigacion Sanitaria of the Instituto de Salud Carlos III (FIS PI10/02869). Partially funded by the European Regional Development Fund "A way of making Europe." The funders had no role in the study design, data collection and analysis, decision to publish, or preparation of the manuscript

Received for publication March 23, 2017; revisions received Jan 22, 2018; accepted for publication Feb 1, 2018; available ahead of print April 5, 2018.

Address for reprints: María Jesús Pérez-Granda, RN, PhD, Clinical Microbiology and Infectious Diseases, Hospital General Universitario Gregorio Marañón, Doctor Esquerdo, 46, 28007 Madrid, Spain (E-mail: massus@hotmail.es). $0022-5223 / \$ 36.00$

Copyright (C) 2018 Published by Elsevier Inc. on behalf of The American Association for Thoracic Surgery

https://doi.org/10.1016/j.jtcvs.2018.02.091
}

Ventilator-associated pneumonia (VAP) is the most frequent infection in patients admitted to intensive care units (ICUs). It is associated with high morbidity and mortality, prolonged hospital stay, ${ }^{1-3}$ and increased health care costs. $^{4-6}$ The main pathogenic mechanism underlying lung infection in VAP is aspiration of contaminated secretions of the upper respiratory tract into the lungs. ${ }^{7-9}$

Measures for preventing VAP can be nonpharmacologic and pharmacologic. The latter group includes oral hygiene with chlorhexidine and selective digestive decontamination

$\square$ Scanning this QR code will take
you to a supplemental video for
the article.




\section{Abbreviations and Acronyms \\ ICU $=$ intensive care unit \\ $\mathrm{MDR}=$ multidrug resistant \\ MHS $=$ major heart surgery \\ $\mathrm{MV}=$ mechanical ventilation \\ SDD $=$ selective digestive decontamination \\ VAP $=$ ventilator-associated pneumonia \\ $\mathrm{XDR}=$ extensively drug resistant}

(SDD) with antimicrobial agents. ${ }^{10-12}$ Despite its efficacy, ${ }^{11,13,14}$ SDD has not been incorporated into the routine of most ICUs, mainly because of the fear of inducing bacterial resistance. ${ }^{15-17}$

In patients undergoing major heart surgery (MHS), the incidence density of VAP is higher than in other populations ${ }^{18}$ despite the introduction of bundles of preventive measures because many risk factors are not amenable to intervention. $^{19}$

Our study assessed the influence of SDD in an MHS-ICU in which other preventive measures had been already introduced. We used only topical antimicrobial agents and evaluated the long-term influence of SDD on the isolation of multidrug-resistant (MDR) microorganisms in the MHSICU population (Video 1).

\section{MATERIALS AND METHODS \\ Hospital Setting and Patients}

Our institution is a general referral hospital with 1550 beds and approximately 50,000 admissions per year. More than 500 MHS procedures are performed annually in our Department of Cardiovascular Surgery, which is a large referral unit.

\section{Study Design}

This was a prospective, interventional study. All consecutive patients from April 2012 to January 2015 received prevention of VAP as the standard of care. The preintervention period went from April 2012 to August 2013. From September 2013 to January 2015 we introduced, on top of the standard care, SDD. Preintervention patients were used as nonconcurrent controls to analyze the ecologic influence of SDD on the MHS-ICU. We compared also the incidence of VAP before the introduction of SDD (17 months) and during the 17 months after introduction.

The bundle of measures for prevention of pneumonia in the MHSICU during the study period (before and during of introduction of SDD), included aspiration of subglottic secretions using a TaperGuard Evac endotracheal tube (Mallinckrodt, St Louis, Mo), cuff pressure maintained at 20 to $30 \mathrm{~mm} \mathrm{Hg}$ and monitored continuously, semirecumbent position $\left(30^{\circ}-45^{\circ}\right)$, and oral hygiene with chlorhexidine. The antibiotic prophylaxis for surgery consisted of $2 \mathrm{~g}$ cefazolin given immediately before surgery and every 8 hours thereafter for a total of 3 doses (patients who were allergic to cefazolin received $1 \mathrm{~g}$ vancomycin twice daily, up to 2 doses). All patients received prophylaxis for gastrointestinal ulcers with proton pump inhibitors. A nasogastric tube was only placed in patients intubated longer than 24 hours who required enteral nutrition or gastric emptying.

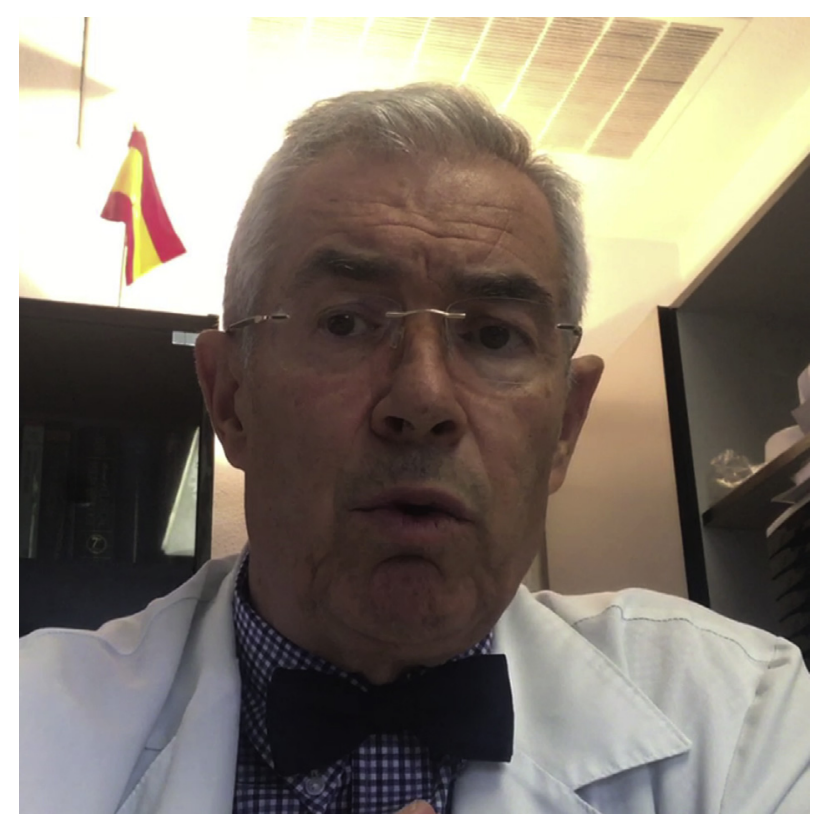

VIDEO 1. Selective digestive decontamination after major heart surgery. Video available at: http://www.jtcvsonline.org/article/S0022-5223(18) 30725-6/fulltext.

SDD was systematically applied to patients who remained under mechanical ventilation (MV) for more than 48 hours. It was also anticipated and started after 24 hours of MV in patients who fulfilled 1 or more of the following criteria: open sternum due to bleeding, hemodynamic instability, ventricular assist device due to cardiogenic shock, and/or neurologic damage type I.

Tracheostomy was not an exclusion criterion. All patients received oral hygiene with $0.12 \%$ chlorhexidine every 6 hours followed by SDD oral paste and digestive solution every 6 hours. Our SDD paste was composed of nystatin, tobramycin, vancomycin, and colistin. The digestive solution contained only colistin, nystatin, and tobramycin.

We did not administer systemic antibiotics as part of the procedure. SDD was stopped at the end of MV or in tracheostomy patients at discharge from the ICU. No surveillance cultures were performed during the study due to the poor predictive value of those cultures in our own institution. ${ }^{20}$

\section{Primary End Point}

The primary end point of the study was the reduction in the incidence density of VAP.

\section{Secondary End Points}

The secondary end points were length of ICU stay, days of MV, mortality rate, cost of antimicrobial drugs during the ICU stay, and ecologic influence on the MHS-ICU population (ie, emergence of antimicrobial resistance, superinfection, and Clostridium difficile infection).

\section{Follow-up}

Physicians from the Departments of Anesthesia and Infectious Diseases monitored patients daily to check for the presence of infection. The infection control team is multidisciplinary and comprises physicians and nurses from the ICU, microbiologists, infectious diseases specialists, and health care workers from the Department of Preventive Medicine. All data of patients undergoing MHS are regularly and prospectively collected in a database, both before and after the introduction of the SDD.

The Ethics Committee of our institution (Hospital Gregorio Marañon) approved the study (code 10/15) and waived the need for informed consent 
because we followed the recommendations of the guidelines for the prevention of VAP.

\section{Sampling in Patients With Suspected Lower Respiratory Tract Infection}

Sampling of the lower respiratory tract in patients with suspected VAP was by endotracheal aspiration, protected specimen brushing, or both. When aspiration was unproductive, we irrigated with $5 \mathrm{~mL}$ Ringer's lactate solution. Secretions obtained by endotracheal aspiration were collected in a Lukens specimen container (Sherwood Medical, Tullamore, Ireland). A sample was considered positive with bacterial counts $\geq 10^{4} \mathrm{CFU} / \mathrm{mL}$ for each microorganism obtained using endotracheal aspiration and $\geq$ $10^{3} \mathrm{CFU} / \mathrm{mL}$ for each microorganism obtained using protected specimen brushing.

All microorganisms were identified using standard methods, and antimicrobial susceptibility was determined according to Clinical and Laboratory Standards Institute recommendations.

\section{Demonstration of VAP}

Patients ventilated for $>48$ hours were diagnosed with VAP based on the presence of new and/or progressive pulmonary infiltrates on the chest radiograph plus $\geq 2$ of the following criteria: fever $>$ $38.5^{\circ} \mathrm{C}$ or hypothermia $<36^{\circ} \mathrm{C}$, leukocytosis $\geq 12 \times 10^{9} / \mathrm{L}$, purulent tracheobronchial secretions, and $\mathrm{a} \geq 15 \%$ reduction in arterial oxygen tension/fraction of inspired oxygen according to the definitions of the Centers for Disease Control and Prevention. ${ }^{21}$ Patients with a clinical pulmonary infection score higher than 6 were also considered to have pneumonia. $^{22}$ The isolation of 1 or more pathogenic microorganisms in significant bacterial counts was required to confirm the diagnosis of VAP. Rate of pneumonia was defined as the number of episodes of pneumonia per days of exposure to mechanical ventilation (ie, incidence density).

The definition for diagnosis of tracheobronchitis was identical to that of VAP in the absence of pulmonary infiltrates. To exclude colonization, patients with tracheobronchitis had to present fever or hypothermia, leukocytosis, purulent tracheobronchial secretions, or a reduction in arterial oxygen tension/fraction of inspired oxygen of $\geq 15 \%$ not attributable to other causes. $^{23,24}$

Unless other evidence was available, we considered as nonpathogenic the isolation (at any concentration) of the following microorganisms in lower respiratory secretions: viridans-group streptococci, coagulase-negative staphylococci, Neisseria spp, Corynebacterium spp, and Candida spp.

\section{Ecologic Influence on the MHS-ICU}

To assess the ecologic influence of SDD on the MHS-ICU population, we compared data from the Department of Microbiology during the 2 study periods, including the proportion of MDR microorganisms (ie, carbapenemase-producing gram-negative bacteria, MDR, or extensively drug-resistant [XDR] Pseudomonas aeruginosa, and methicillin-resistant Staphylococcus aureus isolates).

\section{Statistical Analysis}

Relationships between baseline variables were evaluated before and after implementation of SDD. Baseline comparisons between groups were established by clinical relevance (using the variables of interest according to clinical criteria) following the Consolidated Standards of Reporting

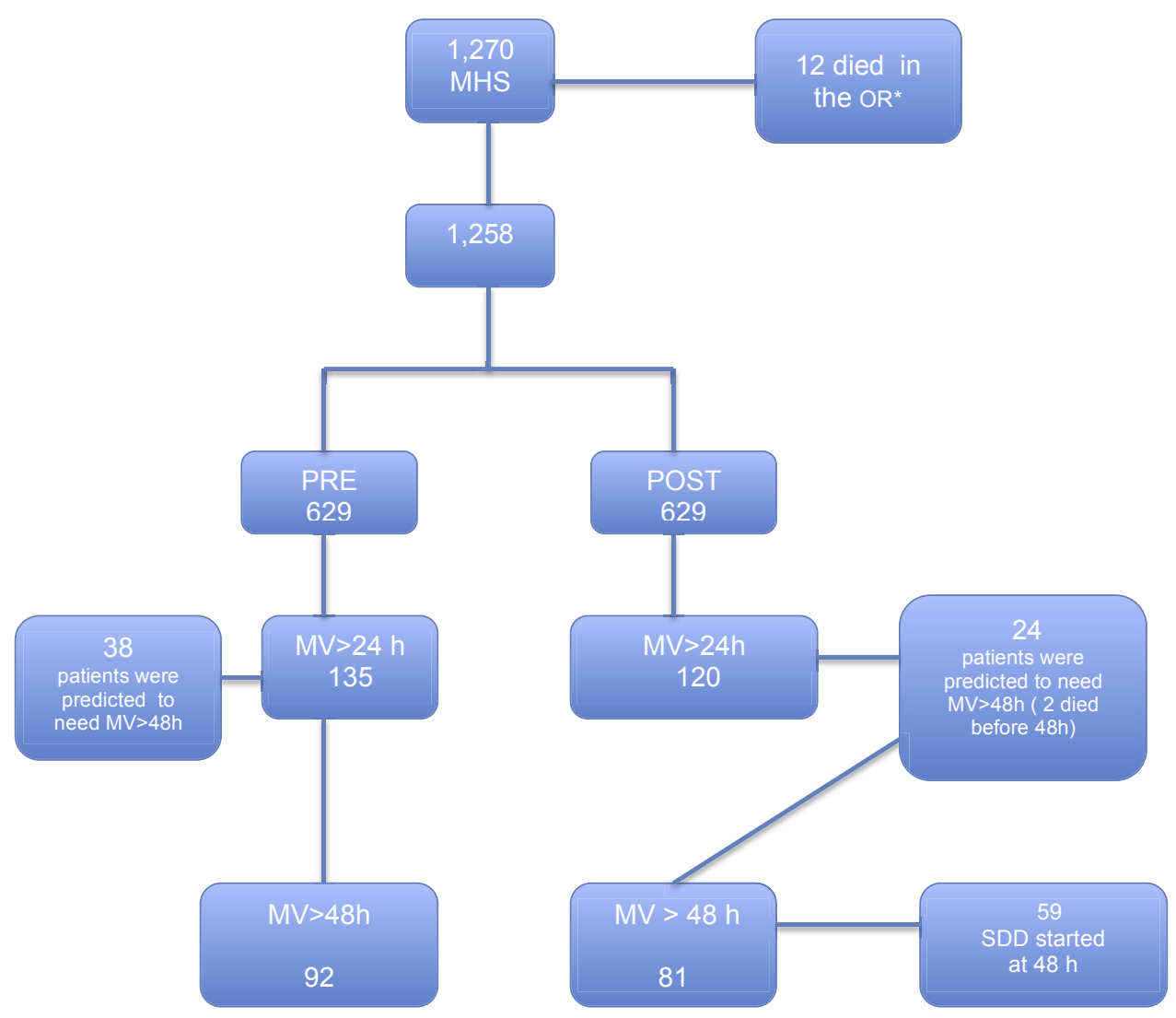

FIGURE 1. Consort diagram of population of study. $M H S$, Major heart surgery; $O R$, operating room; $M V$, mechanical ventilation; $S D D$, selective digestive decontamination. 
Trials Normative for Publication. The qualitative variables appear with their frequency distribution. The quantitative variables are summarized as mean \pm standard deviation and median and interquartile range if the distribution was skewed. Continuous variables were compared using the $t$ test for normally distributed variables or median test for nonnormally distributed variables. The $\chi^{2}$ or Fisher exact test was used to compare categorical variables.

The incidence rates of VAP (event/1000 days of MV) were compared between the groups.

A multivariate logistic regression model adjusted for age, reintubation, days of MV, and SDD was used to assess the influence of SDD in VAP and results were reported as odds ratio and $95 \%$ confidence interval (CI). Time to event was analyzed with the Cox model and is reported as a hazard ratio and $95 \%$ CI. Both models were adjusted by the following variables: age, reintubation, days of MV, and SDD. There was no adjustment for multiplicity in the determination of statistical significance. All statistical tests were 2 -tailed. Statistical significance was set at $P<.05$ for all the tests. The statistical analysis was performed using SPSS 12.0 (IBM-SPSS Inc, Armonk, NY), and STATA 11.0 (StataCorp LLC, College Station, Tex).

\section{RESULTS}

\section{Study Population}

We compared the results obtained before the intervention (April 2012-August 2013) and during the intervention
(September 2013-January 2015). Throughout the study period, 1258 patients underwent MHS (629 per period). Of those, 173 patients $(13.8 \%)$ remained under MV for $\geq 48$ hours and constitute the base of our study: 92 preintervention controls and 81 SDD patients. SDD was started after 48 hours of MV in 59 patients and after 24 hours of MV in 22 high-risk patients according to our criteria (Figure 1).

Both populations (cases and control) were comparable according to age, sex, underlying conditions, European system for cardiac operative risk evaluation score, and acute physiology and chronic health evaluation score. The underlying conditions and surgical variables of both populations are compared in Tables 1 and 2 . The mean \pm standard deviation European system for cardiac operative risk evaluation score of both groups was comparable $(10.1 \pm 2.9$ before the intervention vs $9.4 \pm 4.2$ after the intervention; $P=.25$ ).

\section{Overall Population}

When the overall population was analyzed, we found no significant differences in days of MV, length of ICU

TABLE 1. Baseline characteristics and surgical variables of the study patients

\begin{tabular}{|c|c|c|c|}
\hline & Before SDD $(n=629)$ & During SDD $(n=629)$ & $P$ value \\
\hline \multicolumn{4}{|l|}{ Preoperative } \\
\hline Age, y & $67(57-76)$ & $67(56-75)$ & .27 \\
\hline Sex, F/M & $256 / 373$ & $235 / 394$ & .23 \\
\hline \multicolumn{4}{|l|}{ Underlying conditions } \\
\hline Myocardial infarction & 75 (11.9) & $76(12.1)$ & .93 \\
\hline Congestive heart failure & $69(11.0)$ & $65(10.4)$ & .72 \\
\hline ACVA & $55(8.7)$ & $38(6.0)$ & .06 \\
\hline Chronic obstructive pulmonary disease & $78(12.4)$ & 75 (11.9) & .79 \\
\hline Diabetes mellitus & $156(24.8)$ & $177(28.1)$ & .18 \\
\hline Peptic ulcer disease & $10(1.6)$ & $9(1.4)$ & .81 \\
\hline Peripheral vascular disease & $40(6.4)$ & $36(5.7)$ & .63 \\
\hline Risk, EuroScore (logistic) & $10.1 \pm 11.7$ & $9.4 \pm 4.2$ & .25 \\
\hline Previous cardiac surgery & $91(14.5)$ & $92(14.6)$ & 1.00 \\
\hline Shock & $9(1.4)$ & $7(1.1)$ & .80 \\
\hline Severe reduction of LVEF & $45(7.1)$ & $47(7.5)$ & .82 \\
\hline Severe pulmonary hypertension & $68(10.8)$ & $57(9.1)$ & .30 \\
\hline \multicolumn{4}{|l|}{ Type of surgery } \\
\hline Valve replacement & $275(43.7)$ & $272(43.2)$ & .86 \\
\hline CABG & $146(23.2)$ & $178(28.2)$ & .03 \\
\hline Mixed (valve and CABG) & $69(10.9)$ & $61(9.6)$ & .45 \\
\hline Transplantation & $13(2.2)$ & $19(3.0)$ & .35 \\
\hline Congenital & $10(1.6)$ & $17(2.7)$ & .29 \\
\hline \multicolumn{4}{|l|}{ Surgical data } \\
\hline CPBT, min & $132.3 \pm 59.6$ & 142.0 & .18 \\
\hline Aortic crossclamp time, min & $77.5 \pm 40.6$ & $76.6 \pm 41.6$ & .72 \\
\hline Intra-aortic balloon during surgery & $42(7.0)$ & $50(8.5)$ & .33 \\
\hline
\end{tabular}

Values are presented as median (interquartile range), $\mathrm{n}(\%)$, or mean \pm standard deviation. SDD, Selective digestive decontamination; $A C V A$, acute cerebrovascular accident; EuroSCORE, European system for cardiac operative risk evaluation; $L V E F$, left ventricular ejection fraction, $C A B G$, coronary artery bypass grafting; $C P B T$, cardiopulmonary bypass time. 
TABLE 2. Primary and secondary end points before and after selective digestive decontamination in the overall population of a major heart surgery intensive care unit

\begin{tabular}{|c|c|c|c|}
\hline & Before $(n=629)$ & During $(n=629)$ & $P$ value \\
\hline$(\mathrm{VAP}+$ tracheobronchitis $) / 1000 \mathrm{~d}$ of $\mathrm{MV}$ & 19.74 & 9.28 & .01 \\
\hline Episodes of VAP & 28 & 11 & .008 \\
\hline $\mathrm{VAP} / 1000 \mathrm{~d}$ of $\mathrm{MV}$ & 16.26 & 6.80 & .01 \\
\hline Episodes of tracheobronchitis & 6 & 4 & .52 \\
\hline Tracheobronchitis/1000 d of MV & 3.48 & 2.47 & .83 \\
\hline Total time MV, d & 1722 & 1616 & - \\
\hline Time on MV, d & $2.7 \pm 6.4$ & $2.5 \pm 5.5$ & .61 \\
\hline Time on MV, d & $1(1-1)$ & $1(1-1)$ & .69 \\
\hline Reintubation MV $>48 \mathrm{~h}$ & $34(5.6)$ & $35(5.6)$ & .99 \\
\hline Length of ICU stay, d & $4(3-7)$ & $5(3-7)$ & .82 \\
\hline Transfusion & $384(50.2)$ & $381(49.8)$ & .86 \\
\hline Units transfused & $2(0-3)$ & $1(0-3)$ & .90 \\
\hline Episodes of bacteremia/1000 admissions & 55.0 & 41.47 & .23 \\
\hline Episodes of candidemia/1000 admissions & 1.2 & 2.24 & 1.0 \\
\hline Episodes of CDAD & $5(7.9)$ & $8(13.6)$ & .31 \\
\hline Cost of antimicrobial drugs during the ICU stay/1000 admissions, $€$ & $213.3 \pm 208.4$ & $211.9 \pm 169.0$ & .98 \\
\hline Mortality & $51(8.1)$ & $45(7.2)$ & .52 \\
\hline
\end{tabular}

Values are presented as $\mathrm{n}$, mean \pm standard deviation, median (interquartile range), or $\mathrm{n}(\%) . V A P$, Ventilator-associated pneumonia; $M V$, mechanical ventilation; $I C U$, intensive care unit; CDAD, Clostridium difficile-associated diarrhea.

stay, mortality, or incidence of other infections between the first period (no SDD) and the second period (SDD) (Table 1).

The incidence density of lower respiratory tract infections (combination of VAP and tracheobronchitis) was 19.74 and 9.28 before and during the intervention, respectively $(P=.01)$ (Table 2$)$. The rates of VAP before and during the intervention were $16.26 / 1000$ days and 6.80 episodes/1000 days of MV, respectively $(P=.01)$ (Table $2)$. The rates of tracheobronchitis before and during the intervention were 3.48 and 2.47/1000 days of MV, respectively $(P=.83)$ (Table 2$)$.

We recorded 47 episodes of bacteremia (55.0/1000 admissions) before the intervention and 37 episodes (41.47/ 1000 admissions) during the intervention $(P=.23)$. In the case of candidemia we recorded 1 episode (1.2/1000 admissions) and 2 episodes (2.24/1000 admissions), respectively $(P=1.0)$.

\section{High-Risk Population (Patients Ventilated $>48$ Hours)}

Table 3 shows that the characteristics of high-risk patients (MV $>48$ hours) in both periods of time (with and without SDD) were comparable.

The incidence density of lower respiratory tract infections (combination of VAP and tracheobronchitis) in this high-risk population was 31.39 before the intervention and 14.25 during the intervention $(P=.01)$ (Table 4$)$.
Of 92 high-risk patients, the rates of VAP before and during the intervention were 25.85/1000 days and 12.06 episodes/1000 days of MV, respectively $(P=.04)$. Episodes of tracheobronquitis/1000 days of MV before and during the intervention were 5.54 versus 2.19 , respectively $(P=.41)$. (Table 4).

The median days of MV in the long-term population before and during the intervention was, respectively, 6.0 (range, 4-14.7 days) and 6.0 (range, 3-15.0 days) $(P=.96)$. The episodes of VAP occurred significantly later in patients receiving SDD (day 6 [range, day 3-11] vs day 5 [range, day 3-3-14.5]; $P=.01$ ).

The etiology of VAP during both periods is detailed in Table 5. We only found significant differences in episodes of VAP caused by $P$ aeruginosa between both periods: 13 versus 3 episodes $(P=.03)$.

In a multivariate regression model analysis adjusted for age, reintubation, days of $\mathrm{MV}$, and SDD, we found that SDD was an independent protective factor for the development of VAP (odds ratio, 0.33 ; 95\% CI, 1.13$0.76 ; P=.01)$. When we analyzed the VAP during the period of mechanical ventilation, the hazard ratio was 0.73 (CI, 0.54-0.98; $P=.04$ ), adjusted for age and reintubation.

We were not able to find significant differences in ICU stay, mortality, or other infections in either the overall population or the at-risk population (patients ventilated > 48 hours) (Table 4$)$. 
TABLE 3. Baseline characteristics and surgical variables of patients undergoing major heart surgery on mechanical ventilation for $>48 \mathrm{~h}$

\begin{tabular}{|c|c|c|c|}
\hline & $\begin{array}{c}\text { Before SDD } \\
(\mathbf{n}=92)\end{array}$ & $\begin{array}{l}\text { During SDD } \\
\quad(\mathbf{n}=\mathbf{8 1})\end{array}$ & $P$ value \\
\hline Patients $(\%)$ & 14.6 & 12.9 & .36 \\
\hline \multicolumn{4}{|l|}{ Preoperative } \\
\hline Age, y & $72.5(61.5-78.0)$ & $68.0(59.0-76.0)$ & .06 \\
\hline Sex, F/M & $36 / 56$ & $34 / 47$ & .70 \\
\hline \multicolumn{4}{|l|}{ Underlying conditions } \\
\hline Myocardial infarction & $12(13.0)$ & $11(13.6)$ & .91 \\
\hline Congestive heart failure & 18 (19.6) & $14(17.3)$ & .70 \\
\hline Central nervous system-ACVA & $11(12.0)$ & $10(12.3)$ & .93 \\
\hline Chronic obstructive pulmonary disease & $12(13.0)$ & $12(14.8)$ & .73 \\
\hline Diabetes mellitus & $26(28.3)$ & $20(24.7)$ & .59 \\
\hline Peptic ulcer disease & $2(2.2)$ & $2(2.5)$ & .89 \\
\hline Peripheral vascular disease & $10(10.9)$ & $3(3.7)$ & .07 \\
\hline Risk, EuroSCORE & $18.9 \pm 17.3$ & $15.4 \pm 17.1$ & .18 \\
\hline Severe pulmonary hypertension & $18(19.5)$ & $15(18.5)$ & .87 \\
\hline \multicolumn{4}{|l|}{ Type of surgery } \\
\hline Valve replacement & $37(40.2)$ & $32(39.5)$ & .92 \\
\hline $\mathrm{CABG}$ & $11(12.0)$ & $14(17.3)$ & .32 \\
\hline Mixed (valve and CABG) & $17(18.5)$ & $17(21.5)$ & 0.67 \\
\hline Transplant & $4(4.5)$ & $6(7.4)$ & .42 \\
\hline \multicolumn{4}{|l|}{ Surgical data } \\
\hline CPBT, $\min$ & $157.6 \pm 80.3$ & $156.1 \pm 91.1$ & .90 \\
\hline Aortic crossclamp time, min & $87.5 \pm 57.5$ & $75.2 \pm 58.3$ & .16 \\
\hline Intra-aortic balloon during the surgery & $14(15.6)$ & $26(32.1)$ & .01 \\
\hline
\end{tabular}

Values are presented as median (interquartile range), $\mathrm{n}, \mathrm{n}(\%)$, or mean \pm standard deviation. $S D D$, Selective digestive decontamination; $A C V A$, acute cerebrovascular accident; EuroSCORE, European system for cardiac operative risk evaluation; $C A B G$, coronary artery bypass grafting; $C P B T$, cardiopulmonary bypass time.

\section{Cost of Antimicrobial Agents During ICU Stay}

Cost of antimicrobial drugs during the ICU stay per 1000 admissions, before and after the intervention, were $€ 213.30$ and $€ 211.90(P=.98)$, respectively.

\section{Ecologic Influence of the Implementation of SDD in the MHS-ICU}

To assess the ecologic influence of the introduction of SDD on the MHS-ICU, we analyzed several parameters in

TABLE 4. Primary and secondary end points before and after selective digestive decontamination in the high-risk population (mechanical ventilation $[\mathrm{MV}]>48 \mathrm{~h}$ ) of a major heart surgery intensive care unit

\begin{tabular}{|c|c|c|c|}
\hline & Before $(n=92)$ & During $(\mathbf{n}=\mathbf{8 1})$ & $P$ value \\
\hline$($ Tracheobronchitis+VAP)/1000 d of MV & 31.39 & 14.25 & .01 \\
\hline Episodes of VAP & 28 & 11 & .01 \\
\hline $\mathrm{VAP} / 1000 \mathrm{~d}$ of $\mathrm{MV}$ & 25.85 & 12.06 & .04 \\
\hline Episodes of tracheobronchitis & 6 & 2 & .20 \\
\hline Tracheobronchitis $/ 1000 \mathrm{~d}$ of MV & 5.54 & 2.19 & .41 \\
\hline Total time of MV & 1083 & 912 & .10 \\
\hline Time on MV, d & $6(4-14.7)$ & $6(3-15)$ & .96 \\
\hline Reintubation & $27(29.3)$ & $23(28.4)$ & .85 \\
\hline Length of ICU stay, d & $12.5(7-24.5)$ & $13(8-27.5)$ & .24 \\
\hline Transfusion & $77(86.5)$ & $71(89.9)$ & .50 \\
\hline Units transfused & $4(2-6.7)$ & $5(2-8)$ & .08 \\
\hline Episodes of CDAD & $3(6.8)$ & $6(17.6)$ & .13 \\
\hline Mortality & $32(34.8)$ & $21(25.9)$ & .20 \\
\hline
\end{tabular}

Values are presented as n, $\mathrm{n}(\%)$, or median (interquartile range). VAP, Ventilator-associated pneumonia; $M V$, mechanical ventilation; ICU, intensive care unit; $C D A D, C l o s-$ tridium difficile-associated diarrhea. 
TABLE 5. Microorganisms isolated during episodes of ventilatorassociated pneumonia before and during selective digestive decontamination

\begin{tabular}{lccc}
\hline & $\begin{array}{c}\text { Before } \\
(\mathbf{n = 2 8})\end{array}$ & $\begin{array}{c}\text { During } \\
(\mathbf{n = 1 1 )}\end{array}$ & $\boldsymbol{P}$ value \\
\hline $\begin{array}{l}\text { Methicillin-susceptible } \\
\quad \text { Staphylococcus aureus }\end{array}$ & 1 & 2 & .91 \\
Haemophilus influenzae & 4 & 0 & .16 \\
\hline Enterobacteriaceae & 15 & 5 & .06 \\
Pseudomonas aeruginosa & 13 & 3 & .03 \\
Virus & 1 & 1 & .53 \\
\hline
\end{tabular}

the whole population admitted to the MHS-ICU before and after the intervention.

Table 6 shows data obtained from the Department of Microbiology on the incidence per $1000 \mathrm{MHS} / \mathrm{ICU}$ admissions according to several parameters. We found no significant differences in the number of patients with $\geq 1$ isolates of gram-negative carbapenemase-producing gram-negative bacteria or number of patients with $\geq 1$ methicillin-resistant $S$ aureus isolates.

We found a significant reduction in the number of patients with $\geq 1$ isolates of MDR or XDR $P$ aeruginosa $(P<.001)$ during the second period (Table 6$)$. The number of patients with $\geq 1 \mathrm{MDR}$ microorganism was 18 and 10 $(P=.10)$ for each period, respectively.

\section{DISCUSSION}

In a busy MHS-ICU, the implementation of SDD without parenteral antibiotics in the high-risk population remaining under MV for more than 48 hours, reduced the rate of VAP and delayed its appearance. This intervention did not promote the emergence of antibiotic resistance, neither in the high-risk population nor in the overall population. We were not able to demonstrate a significant influence on mortality in the overall population.

VAP is the most frequent infection after MHS, with incidence rates ranging from $5.7 \%$ to $21.6 \%$, although incidence can reach $46 \%$ in high-risk patients, who must remain under MV for more than 48 hours. ${ }^{19}$ The effect of SDD with topical antibiotics (with or without parenteral antibiotics) remains open to debate ${ }^{25-27}$; however, this measure was associated with a reduction in mortality in a recent meta-analysis. $^{13,28}$

Most data on the efficacy of SDD are obtained from general ICUs, as opposed to MHS-ICUs. ${ }^{11,16,29}$ Our data also confirm the efficacy of SDD in this specific group of patients.

Although the major concern regarding SDD is the potential selection of drug-resistant microorganisms, several meta-analyses did not confirm this fear. In those series, data on resistant microorganisms were obtained over short periods of time and mainly in the exposed population. ${ }^{15,17,29-33}$

Our study shows that MDR organisms causing colonization or infection did not appear in the overall population of our MHS-ICU and were collected over a relatively long period of observation. In fact, we found that the number of patients with $\geq 1$ isolates of MDR or XDR P aeruginosa decreased during the period when SDD was used and that the number of other MDR bacteria did not increase.

We decided not to use parenteral antibiotics because our group had previously shown that even short courses of no

TABLE 6. Ecologic influence of selective digestive decontamination

\begin{tabular}{|c|c|c|c|}
\hline & $\begin{array}{c}\text { April } \\
\text { 2012-August } \\
2013 \text { (before) }\end{array}$ & $\begin{array}{l}\text { September } \\
\text { 2013-January } \\
2015 \text { (after) }\end{array}$ & $P$ value \\
\hline Total admissions for major heart surgery & 854 & 892 & .59 \\
\hline ICU length of stay, $d$ & 5362 & 5610 & .59 \\
\hline Number of samples with any bacteriological request from intensive care unit & 531 & 505 & .06 \\
\hline Number of samples with $\geq 1$ bacterial isolates* & 307 & 217 & $<.001$ \\
\hline Number of patients with $\geq 1$ bacterial isolates* & $103(12.0)$ & $85(9.5)$ & .12 \\
\hline Number of patients with $\geq 1$ MRSA isolates* & $3(0.3)$ & $1(0.1)$ & .59 \\
\hline Number of patients with $\geq 1$ linezolid-resistant Staphylococcus aureus isolates* & - & - & NA \\
\hline Number of patients with $\geq 1$ isolates of MDR or XDR Pseudomonas aeruginosa* & $9(1.0)$ & $0(0)$ & .01 \\
\hline Number of patients with $\geq 1$ isolates of ESBL-producing Enterobacteriaceae* & $6(0.7)$ & $9(1.0)$ & .66 \\
\hline Number of patients with $\geq 1$ isolates of gram-negative carbapenemase- producing gram-negative bacteria* & $1(0.19)$ & $1(0.1)$ & 1.47 \\
\hline Number of patients with $\geq 1$ isolates of MDR or XDR Acinetobacter baumannii* & - & - & NA \\
\hline Number of patients with $\geq 1$ MDR microorganisms* & $18(2.1)$ & $10(1.1)$ & .15 \\
\hline
\end{tabular}

ICU, Intensive care unit; MRSA, methicillin-resistant Staphylococcus aureus; NA, not available; $M D R$, multidrug-resistant; XDR, extensively drug-resistant (from PMID 21793988); ESBL, extended-spectrum beta-lactamase. *Number of episodes (episodes per 1000 admissions). 
more than 3 days of intravenous linezolid caused an increase in the number of linezolid-resistant Staphylococcus spp isolates (coagulase-negative staphylococci and $S$ aureus) in our MHS-ICU. ${ }^{34}$

The effect of SDD on bacteremia is particularly interesting. Bacteremia acquired by patients in the ICU is associated with high attributable mortality, especially in those undergoing MV or who have pneumonia as the source of bacteremia. ${ }^{35}$ We observed a decreasing trend in the frequency of bacteremic episodes during the second period, although the differences did not reach statistical significance.

Our study is limited by the fact that we enrolled only the population undergoing MHS; therefore, our data cannot necessarily be extrapolated to other ICU populations. The design of our study did not include concurrent controls and a Hawthorne effect cannot be excluded with this design.

\section{CONCLUSIONS}

We found that SDD without parenteral antibiotics can reduce the incidence and delay onset of VAP in high-risk patients after MHS. SDD had no ecologic influence on the incidence of MDR microorganisms in the MHS-ICU. In our opinion, SDD should be systematically applied to all patients requiring MV $>48$ hours after MHS.

\section{Conflict of Interest Statement}

Authors have nothing to disclose with regard to commercial support.

The authors thank Thomas O'Boyle for providing help in the preparation of the English version of the manuscript.

\section{References}

1. Rello J, Ollendorf DA, Oster G, Vera-Llonch M, Bellm L, Redman R, et al. Epidemiology and outcomes of ventilator-associated pneumonia in a large US database. Chest. 2002;122:2115-21.

2. Bouza E, Hortal J, Munoz P, Pascau J, Perez MJ, Hiesmayr M. Postoperative infections after major heart surgery and prevention of ventilator-associated pneumonia: a one-day European prevalence study (ESGNI-008). J Hosp Infect. 2006;64:224-30

3. Sinuff T, Muscedere J, Cook D, Dodek P, Heyland D. Ventilator-associated pneumonia: improving outcomes through guideline implementation. J Crit Care. 2008;23:118-25.

4. Greco G, Shi W, Michler RE, Meltzer DO, Ailawadi G, Hohmann SF, et al. Costs associated with health care-associated infections in cardiac surgery. $J$ Am Coll Cardiol. 2015;65:15-23.

5. Mathai AS, Phillips A, Kaur P, Isaac R. Incidence and attributable costs of ventilator-associated pneumonia (VAP) in a tertiary-level intensive care unit (ICU) in northern India. J Infect Public Health. 2015;8:127-35.

6. Kyaw MH, Kern DM, Zhou S, Tunceli O, Jafri HS, Falloon J. Healthcare utilization and costs associated with $S$. aureus and P. aeruginosa pneumonia in the intensive care unit: a retrospective observational cohort study in a US claims database. BMC Health Serv Res. 2015;15:241.

7. Rumbak MJ. The pathogenesis of ventilator-associated pneumonia. Semina Respir Crit Care Med. 2002;23:427-34.

8. Blot SI, Poelaert J, Kollef M. How to avoid microaspiration? A key element for the prevention of ventilator-associated pneumonia in intubated ICU patients. BMC Infect Dis. 2014;14:119.
9. Benitez L, Ricart M. [Pathogenesis and environmental factors in ventilatorassociated pneumonia]. Enfermedades Infec Microbiolog Clin. 2005;23(Suppl 3):10-7.

10. Zhao D, Song J, Gao X, Gao F, Wu Y, Lu Y, et al. Selective oropharyngeal decontamination versus selective digestive decontamination in critically ill patients: a meta-analysis of randomized controlled trials. Drug Design Dev Ther. 2015;9: 3617-24.

11. Schnabel RM, Scholte JB, Van Der Velden KE, Roekaerts PM, Bergmans DC Ventilator-associated pneumonia rates after introducing selective digestive tract decontamination. Infect Dis (London, England). 2015;47:650-3.

12. Cutler LR, Sluman P. Reducing ventilator associated pneumonia in adult patients through high standards of oral care: a historical control study. Intens Crit Care Nurs. 2014:30:61-8.

13. Roquilly A, Marret E, Abraham E, Asehnoune K. Pneumonia prevention to decrease mortality in intensive care unit: a systematic review and meta-analysis. Clin Infect Dis. 2015;60:64-75.

14. Hurley JC. Is selective decontamination of the digestive tract safe? Clin Infect Dis. 2015;60:1729-30.

15. Daneman N, Sarwar S, Fowler RA, Cuthbertson BH. Effect of selective decontamination on antimicrobial resistance in intensive care units: a systematic review and meta-analysis. Lancet Infect Dis. 2013;13:328-41.

16. Reis Miranda D, Citerio G, Perner A, Dimopoulos G, Torres A, Hoes A, et al. Use of selective digestive tract decontamination in European intensive cares: the ifs and whys. Minerva Anestesiologica. 2015;81:734-42.

17. Plantinga NL, Bonten MJ. Selective decontamination and antibiotic resistance in ICUs. Crit Care (London, England). 2015;19:259.

18. Hortal J, Munoz P, Cuerpo G, Litvan H, Rosseel PM, Bouza E. Ventilator-associated pneumonia in patients undergoing major heart surgery: an incidence study in Europe. Critical Care (London, England). 2009;13:R80.

19. Hortal J, Giannella M, Perez MJ, Barrio JM, Desco M, Bouza E, et al. Incidence and risk factors for ventilator-associated pneumonia after major heart surgery. Intens Care Med. 2009;35:1518-25.

20. Bouza E, Perez A, Munoz P, Jesus Perez M, Rincon C, Sanchez C, et al. Ventilator-associated pneumonia after heart surgery: a prospective analysis and the value of surveillance. Critical Care Med. 2003;31:1964-70.

21. Garner JS, Jarvis WR, Emori TG, Horan TC, Hughes JM. CDC definitions for nosocomial infections, 1988. Am J Infect Control. 1988;16:128-40.

22. Pugin J. [The diagnosis of pneumonia in the ventilated patient]. Schweiz Medizin Wochenschr. 1990;120:1672-7.

23. Nseir S, Di Pompeo C, Pronnier P, Beague S, Onimus T, Saulnier F, et al. Nosocomial tracheobronchitis in mechanically ventilated patients: incidence, aetiology and outcome. Eur Respir J. 2002;20:1483-9.

24. Niederman MS. Hospital-acquired pneumonia, health care-associated pneumonia, ventilator-associated pneumonia, and ventilator-associated tracheobronchitis: definitions and challenges in trial design. Clin Infect Dis. 2010;51(Suppl 1):S12-7.

25. Marshall AP, Weisbrodt L, Rose L, Duncan E, Prior M, Todd L, et al. Implementing selective digestive tract decontamination in the intensive care unit: a qualitative analysis of nurse-identified considerations. Heart Lung. 2014;43:13-8.

26. Price RJ, Cuthbertson BH. Selective decontamination of the digestive tract and oropharynx: after 30 years of debate is the definitive answer in sight? Curr Opin Crit Care. 2016;22:161-6.

27. Silvestri L, Petros AJ, De La Cal MA, Visintin S. Selective digestive decontamination. Why are intensivists more "resistant" than microorganisms? Minerva Anestesiologica. 2011;77:658-9.

28. Price R, MacLennan G, Glen J. Selective digestive or oropharyngeal decontamination and topical oropharyngeal chlorhexidine for prevention of death in general intensive care: systematic review and network meta-analysis. BMJ Clin Res Ed. 2014;348:g2197.

29. de Smet AM, Kluytmans JA, Blok HE, Mascini EM, Benus RF, Bernards AT, et al. Selective digestive tract decontamination and selective oropharyngeal decontamination and antibiotic resistance in patients in intensive-care units: an open-label, clustered group-randomised, crossover study. Lancet Infect Dis. 2011;11:372-80.

30. Noteboom Y, Ong DS, Oostdijk EA, Schultz MJ, de Jonge E, Purmer I, et al. Antibiotic-induced within-host resistance development of gram-negative bacteria in patients receiving selective decontamination or standard care. Crit Care Med. 2015;43:2582-8.

31. Brink AJ, Coetzee J, Corcoran C, Clay CG, Hari-Makkan D, Jacobson RK, et al. Emergence of OXA-48 and OXA-181 carbapenemases among Enterobacteriaceae in South Africa and evidence of in vivo selection of colistin resistance as 
a consequence of selective decontamination of the gastrointestinal tract. J Clin Microbiol. 2013;51:369-72.

32. Halaby T, Al Naiemi N, Kluytmans J, van der Palen J, VandenbrouckeGrauls CM. Emergence of colistin resistance in Enterobacteriaceae after the introduction of selective digestive tract decontamination in an intensive care unit. Antimicrob Agents Chemother. 2013;7:3224-9.

33. Lubbert C, Faucheux S, Becker-Rux D, Laudi S, Durrbeck A, Busch T, et al. Rapid emergence of secondary resistance to gentamicin and colistin following selective digestive decontamination in patients with KPC-2-producing Klebsiella pneumoniae: a single-centre experience. Int J Antimicrob Agents. 2013;42: 565-70.
34. Bouza E, Granda MJ, Hortal J, Barrio JM, Cercenado E, Munoz P. Pre-emptive broad-spectrum treatment for ventilator-associated pneumonia in high-risk patients. Intens Care Med. 2013;39:1547-55.

35. Hurley JC. Topical antibiotics as a major contextual hazard toward bacteremia within selective digestive decontamination studies: a meta-analysis. BMC infect Dis. 2014;14:3842.

Key Words: prevention, ventilator-associated pneumonia, selective digestive decontamination, nosocomial pneumonia

Readers who found these articles interesting may also like to read the following papers found in recent and future issues of our sister publications, Seminars in Thoracic and Cardiovascular Surgery and Operative Techniques in Thoracic and Cardiovascular Surgery!

\section{Adult: Perioperative Management}

ORIGINAL SUBMISSION: Early Outcomes with Rapid- Deployment Versus Stented Biological Valves: A Propensity-Match Analysis. Anthony Nguyen. Semin Thoracic Surg 2018:16-23.

Editorial Commentary: Rapid-Deployment Aortic Valve Replacement: Clear Benefits Without a Clear Target Patient Population. Craig M. Jarrett. Semin Thoracic Surg 2018:24-25.

ORIGINAL SUBMISSION: Randomized Trial of Carnitine for the Prevention of Perioperative Atrial Fibrillation. Farzaneh Dastan. Semin Thoracic Surg 2018:7-13.

Editorial Commentary: Preventing Postoperative Atrial Fibrillation: Is There One Best Option? Vincent R. Conti. Semin Thoracic Surg 2018:14-15. 